\title{
PODER E VOZ: A IMPORTÂNCIA DA PARTICIPAÇÃO DE CRIANÇAS E ADOLESCENTES EM POLÍTICAS PÚBLICAS
}

\author{
Vanessa Therezinha Sousa de Almeida* \\ Edna Raquel Rodrigues Santos Hogemann ${ }^{* *}$
}

Resumo: Analisa representações sociais sobre o direito de participação de crianças e adolescentes em políticas públicas, como parte integrante do rol de seus direitos. Utiliza o parâmetro principiológico do melhor interesse e experiências relevantes de implementação da participação infanto-juvenil em políticas públicas. Recorre às bases do constitucionalismo naquilo que é pertinente ao pensamento de Barbara Bennett Woodhouse, e concepções afins. Classifica-se a pesquisa como exploratória, qualitativa, com recursos bibliográficos e método dialético, evidenciando reconhecimento e consideração da visão e voz de crianças e adolescentes para fortalecer o direito à participação, na perspectiva do exercício democrático da convivência social e política.

Palavras-chave: crianças e adolescentes; direito de participação; políticas públicas; direitos humanos.

\section{POWER AND VOICE: THE IMPORTANCE OF CHILDREN AND ADOLESCENTS' PARTICIPATION IN PUBLIC POLICIES}

\begin{abstract}
It analyses social representations about right to participation of children and adolescents in public policies, as an integral part of the list of their rights. It uses principle parameter of best interest and relevant experiences in implementation of children's participation in public policies. It resorts to foundations of constitutionalism in what is pertinent to Barbara Bennett Woodhouse's thought, and similar conceptions. Research is classified as exploratory, qualitative, with bibliographic resources and dialectical method, showing recognition and consideration of vision and voice of children and adolescents to strengthen right to participation, from perspective of democratic exercise of social and political coexistence.
\end{abstract}

Keywords: children and adolescent; participation; public policies; human rights.

\footnotetext{
* Promotora de Justiça do Ministério Público do Estado de São Paulo, Bacharel em Direito (2006) e Especialista em Direito Civil e Processual Civil (2008), ambos pelo Centro Universitário Salesiano de São Paulo, Unidade de Lorena. Atualmente, é Mestranda em Direito pela Universidade Federal do Estado do Rio de Janeiro (UNIRIO) e membro do Grupo Direito Humanos e Transformação Social (CNPq). E-mail: va.tsalmeida@ edu.unirio.br.

** Pós-doutora em Direito (UNESA), doutora e mestre em Direito (UGF). Especialista em Bioética pela Cátedra em Bioética da UNESCO. Especialista em Direitos Humanos pela Universidade de Coimbra, Portugal. Professora permanente do Programa de Pós-Graduação em Direito da Universidade Federal do Estado do Rio de Janeiro. Decana do Centro de Ciências Jurídicas, Políticas e de Administração, da Universidade Federal do Estado do Rio de Janeiro. Coordenadora do Grupo Direito Humanos e Transformação Social (CNPq). E-mail: edna.r.hogemann@unirio.br.
} 


\section{INTRODUÇÃO}

As Kate Gilmore, the Deputy High Commissioner for Human Rights of the United Nations, said in openinhumang the DGD, adults have failed children and young people in so many ways, and are continuing to do so. As such, she asserted, it is time that we all start to listen to children and young people (KIRK, 2019, p. 419) ${ }^{1}$.

A democracia participativa sempre foi um desafio em nosso país. Nossa formação histórica envolve um passado, não muito distante, de um perfil burocrático e hierarquizado na tomada das decisões, lastreado pelo clientelismo, que se vale de uma tecnocracia para evitar mudanças reais, com características nitidamente oligárquicas. Na medida em que o poder, tanto em nível nacional quanto regional ou local, é exercido por um grupo pequeno de pessoas, em geral, vinculadas à mesma família, partido ou grupo econômico, há pouca abertura democrática.

Discorrer sobre democracia participativa significa, entre outras, a discussão da construção de formas alternativas de desenvolvimento de relações sociais fundamentadas tanto na afirmação quanto na real efetividade de Direitos Humanos, a partir de organizações públicas cuja vocação é a de atuar formalmente na perspectiva do atendimento das necessidades da sociedade. Importa afirmar e apontar a importância dos atores sociais no processo democrático. Aqui começa o objeto da reflexão do presente ensaio.

Não há muitos textos tratando da temática da infância e da juventude quando se debate o exercício da cidadania. Em geral, o que se costuma perceber é um processo de exclusão do acesso ao direito à participação social e política. Isso se dá porque permanece, em nossa sociedade, a ideia de que cidadania é sinônimo de direito de votar e de ser votado. Portanto, crianças e adolescentes, que não exercem o poder/dever do povo, estariam “invisíveis" aos olhos da cidadania. Faz-se necessário, então, que não se esqueça: é fato que crianças e adolescentes até os dezesseis anos não podem votar, mas, isso não significa que tenham que ficar alheios às decisões políticas de seu núcleo familiar, da comunidade/bairro, da cidade e do país.

Sobre a participação desses atores no ciclo das políticas públicas como forma, inclusive, de respeito à condição deles de sujeitos de direitos, o presente ensaio pretende responder às seguintes indagações: (a) em que medida crianças e adolescentes revelam-se

\footnotetext{
1 "Como a Alta Comissária Adjunta para os Direitos Humanos das Nações Unidas, Kate Gilmore, afirmou ao abrir a DGD, os adultos falharam com as crianças e jovens de tantas maneiras, e continuam a fazê-lo. Como tal, afirmou ela, é tempo de todos começarmos a ouvir as crianças e os jovens" (tradução nossa).
} 
como atores sociais?; (b) eles podem participar da formulação de políticas públicas?; (c) caso possam participar, essa participação possui limites?

As hipóteses iniciais são de que eles são, sim, sujeitos de direitos, que devem ter voz dentro da sociedade, inclusive, para participar da solução de problemas públicos, contribuindo com a formação de agenda pública. Nesse sentido, este ensaio tem como objetivo destacar algumas ideias com a pretensão futura de revisitar as bases ideológicas dos Direitos Humanos que consagram direitos e garantias de crianças e adolescentes sob um ethos democrático participativo. Para tanto, realiza-se uma análise reflexiva das abordagens acerca da matéria, tendo em vista os contextos locais e as suas diversas concepções, com o respaldo principiológico da promoção do melhor interesse da criança e do adolescente em suas realidades socioculturais situadas, assim como os arranjos sociais significativos para cada um desses contextos. Apresentam-se, como referencial teórico, as ideias desenvolvidas por Barbara Bennett Woodhouse (2003), reforçadas por algumas abordagens não menos relevantes trazidas ao longo do ensaio. Utiliza-se o método de pesquisa exploratória, com recursos bibliográficos e viés dialético.

O tema mostra-se relevante frente às poucas iniciativas destinadas a estimular e garantir a voz e participação de crianças e adolescentes, em especial, em questões que dizem respeito aos seus interesses, como é o caso, por exemplo, das estruturas necessárias para os Centros Integrados de atendimento de violência sexual infantil. Ademais, a participação de crianças e de adolescentes ganha importância quando se pensa no processo de avanços e retrocessos característico dos direitos humanos e na necessidade contínua de conferir-lhes efetividade.

Com a finalidade de facilitar a compreensão do material pesquisado e a sequência do raciocínio seguido, este ensaio, inicialmente, volta-se à análise da condição de crianças e adolescentes como atores sociais. Depois, analisa-se as previsões legislativas sobre o direito de participação de crianças e adolescentes, trazendo relatos a respeito de algumas experiências relevantes sobre a questão e apresentando determinados espaços já existentes para o exercício da participação de crianças e adolescentes para, ao final, trazer a consolidação dos resultados das pesquisas.

\section{CRIANÇAS E ADOLESCENTES COMO ATORES SOCIAIS}


My message is that we'll be watching you. This is all wrong. I shouldn't be up here. I should be back in school on the other side of the ocean. Yet, you all come to us young people for hope. How

dare you!

You have stolen my dreams and my childhood with your empty words and yet

I'm one of the lucky ones. People are suffering. People are dying. Entire ecosystems are collapsing. We are in the beginning of a mass extinction and all you can talk about is money and fairytales of eternal economic growth.

How dare you!

For more than 30 years, the science has been crystal clear. How dare you continue to look away and come here saying that you're doing enough when the politics and solutions needed are still nowhere in sight.

You say you hear us and that you understand the urgency, but no matter how sad and angry I am, I do not want to believe that. Because if you really understood the situation and still kept on failing to act then you would be evil and that I refuse to believe.

You are failing us, but the young people are starting to understand your betrayal. The eyes of all future generations are upon you and if you choose to fail us, I say: We will never forgive you.

We will not let you get away with this. Right here, right now is where we draw the line. The world is waking up and change is coming, whether you like it or not (THUNBERG, 2019). ${ }^{2}$

Quem ouviu o discurso eloquente de Greta Thunberg - ativista ambiental sueca, nascida em 2003 - na Conferência das Nações Unidas sobre Mudanças Climáticas (COP 25), que aconteceu em Madrid, na Espanha, em 2019, e seus desdobramentos em nível mundial, percebe claramente a capacidade de mobilização que a voz de crianças e adolescentes possui quando estes se encontram devidamente empoderados. Todavia, para a compreensão do alcance do direito à participação em políticas públicas, o primeiro passo deve ser a análise da condição deles como sujeito de direitos e atores sociais.

O reconhecimento como sujeitos de direitos e a extensão dos direitos humanos a crianças e adolescentes encontram como importante fonte a Convenção dos Direitos das

\footnotetext{
2 "A minha mensagem é que vamos estar de olho em si. Isto está tudo errado. Eu não devia estar aqui em cima. Deveria estar de volta à escola do outro lado do oceano. No entanto, todos vocês vêm até nós, jovens, em busca de esperança. Como ousam! Vocês roubaram os meus sonhos e a minha infância com as vossas palavras vazias e, no entanto, eu sou um dos sortudos. As pessoas estão a sofrer. As pessoas estão a morrer. Ecossistemas inteiros estão a colapsar. Estamos no início de uma extinção em massa e só se pode falar de dinheiro e de contos de fadas de crescimento económico eterno. Como se atreve! Durante mais de 30 anos, a ciência tem sido cristalina. Como ousa continuar a olhar para o lado e vir aqui dizer que está a fazer o suficiente quando a política e as soluções necessárias ainda não estão à vista. Diz que nos ouve e que compreende a urgência, mas por muito triste e zangada que eu esteja, não quero acreditar nisso. Porque se realmente compreendessem a situação e continuassem a não agir, então seriam maus e eu recuso-me a acreditar nisso. [...] Está a falhar-nos, mas os jovens estão a começar a compreender a sua traição. Os olhos de todas as gerações futuras estão postos em si e se optar por nos falhar, digo eu: nunca vos perdoaremos. Não o deixaremos escapar impune. Aqui mesmo, neste momento, é aqui que traçamos a linha. O mundo está a acordar e a mudança está a chegar, quer queiram quer não" (tradução nossa).
} 
Crianças (UNICEF, 1989). Este documento, contudo, fez mais do que isso. Ele trouxe o reconhecimento da condição de vulnerabilidade e os princípios da proteção integral e da prioridade absoluta para esse grupo, dos quais se extrai a necessidade de proteção a sua condição de pessoas em desenvolvimento. No Brasil, a mesma previsão pode ser encontrada na Constituição Federal (BRASIL, 1988) e no Estatuto da Criança e do Adolescente (BRASIL, 1990).

Outro princípio que pode ser extraído dos diplomas referidos é o princípio do melhor interesse, que, segundo Mônaco (2005, p. 181-184), deve ser considerado pelo Estadoadministrador em todo o ciclo das políticas públicas, pelo Estado-juiz nos casos concretos colocados em sua apreciação, pela família nas decisões relativas a crianças e adolescentes e pela sociedade como um todo. Com isso, é incoerente negar que crianças e adolescentes podem auxiliar na definição do melhor interesse e de suas prioridades.

Sobre a condição de crianças e adolescentes como sujeitos de direitos, é importante trazer as lições de Veronese:

Crianças e adolescentes não são mais pessoas capitis deminutae, mas sujeitos de direitos plenos; eles têm, inclusive, mais direitos que outros cidadãos, isto é, eles têm direitos específicos depois indicados nos títulos sucessivos da primeira parte; e estes direitos específicos são exatamente aqueles que têm que lhes assegurar o desenvolvimento, o crescimento, o cumprimento de suas potencialidades, o tornar-se cidadãos adultos livres e dignos (VERONESE, 2018, p. 60).

Note-se, portanto, que negar a crianças e adolescentes sua condição de sujeito de direitos é criar dúvidas sobre sua qualidade como seres humanos, assim como sobre a igualdade e dignidade que merecem (INVERNIZZI; WILLIANS, 2016, p. 22; KIRK, 2019). Não se ousa dizer que eles não têm direito à vida, à saúde e à integridade, mas, no que se refere ao direito de participação, não são poucas as vozes que lhes colocam entraves ao exercício.

Assim, a condição de sujeitos de direitos de crianças e adolescentes é pacificada nos textos legais no Brasil desde a superação da doutrina da situação irregular. Frise-se, como os direitos humanos não são uma questão apenas de lei, mas, também, de práticas cotidianas e de luta diária para sua implementação e funcionamento (BAXI, 2006, p. 183). Nesse sentido, o reconhecimento de crianças e adolescentes como sujeitos de direitos passa pela constatação de que estes também possuem o direito à luta pela transformação social (SARMENTO; FERNANDES; TOMÁS, 2007, p. 194).

Na prática, a resistência ou o não reconhecimento materializa-se pelo silenciamento 
de crianças e adolescentes, excluindo-os da participação dos processos de interpretação e implementação dos direitos humanos em benefício desse grupo (Ibid., p. 185). Não é por outra razão que já se destacou que a autonomia e a competência desses sujeitos para ter e expressar seus pontos de vista ainda é um ponto não pacífico em relação a todos os temas.

É nesse contexto de disputa para reconhecê-los como protagonistas de sua própria história e da história de nossa sociedade, enquanto projeto coletivo, que ganha importância a aceitação de que crianças e adolescentes não só são sujeitos de direitos, mas, também, atores sociais e políticos que influenciam na formação da agenda pública (SECCHI; COELHO; PIRES, 2020, p. 205), seja na condição de um grupo organizado, seja individualmente, como catalizador de discussões sobre problemas relevantes.

Desse modo, não faz sentido considerar crianças e adolescentes como sujeitos de direitos e não permitir a eles qualquer voz nas políticas públicas (TOMÁS, 2007, p. 51; RODRÍGUEZ; VUANELLO, 2021), retirando-lhes, portanto, o poder de demandar o respeito aos seus direitos, à nomeação de novos direitos humanos e à interpretação dos direitos que entendem mais adequada (CHENEY, 2013, p. 94). Tal postura implicaria no silenciamento dos anseios (Ibid.) de aproximadamente 53,7 milhões de brasileiros (UNICEF, 2021), ou seja, de um grupo social que representa quase $1 / 4$ da população do Brasil, assim como em sua alienação de toda política que tem o potencial de interferir em seu cotidiano e, mais do que isso, de gerar consequências irreparáveis ao futuro deles e das gerações futuras (INVERNIZZI; MILNE, 2002, p. 406; SARMENTO; FERNANDES; TOMÁS, 2007, p. 185).

A posição restritiva à participação de crianças e adolescentes é alarmante quando se percebe que o percentual de crianças está em declínio, com a inversão em alguns locais da pirâmide etária. Ora, é factível que, neste contexto, haja um aumento de lobbies para os idosos, sendo até mesmo possível perguntar quem falará pelas crianças e como será possível chegar à justiça intergeracional (PROUT, 2000, p. 311-312).

O tema do envolvimento de crianças e adolescentes em políticas públicas já fazia parte de uma preocupação presente na Declaração dos Direitos das Crianças (Princípio X). A declaração, portanto, é compatível com a visão de crianças e adolescentes podem contribuir para construção de espaços sociais melhores (RODRIGUEZ; VUANELLO, 2021, p. 328). Não permitir a eles participar é o mesmo que negar a possibilidade de contribuir para a construção do discurso e para a prática de direitos humanos (GOODALE, 2007, p. 24), assim como significa aceitar que as previsões em tratados não são coerentes com a prática e que a 
priorização é feita por adultos em detrimento da participação de crianças e, por vezes, contra os interesses delas (SHIVJI, 2002, p. 03).

Nota-se, outrossim, que é ilusório pensar que sempre se leva em conta os interesses infanto-juvenis no processo de formulação e implementação de políticas públicas por adultos, ainda mais diante do paternalismo característico do processo dialético entre crianças e adolescentes versus adultos (HORSFALL, 2013; CASSIDY et al., 2017).

Há, afinal, uma forte noção ainda enraizada de que crianças e adolescentes são "para serem vistos e não ouvidos" e de que são os cidadãos do futuro, mas estão afastados do convívio coletivo e dos espaços públicos (PROUT, 2000; WOODHOUSE, 2003, p. 752; SARMENTO; FERNANDES; TOMÁS, 2007, p. 188; VIVIERS; LOMBARD, 2013, p. 8). Para respeito aos direitos humanos de crianças e adolescentes, há necessidade de que a interpretação e leitura destes direitos sejam feitas de forma a colocá-los no centro e, com isso, ressaltar a importância de dar oportunidade à expressão de suas visões de mundo e opiniões, bem como seu envolvimento em questões que identifiquem como importantes (WOODHOUSE, 2003, p. 751; PÖSÖ; ENROOS, 2017, p. 737).

A apropriada participação de crianças e adolescentes só é possível ser desenvolvida em uma atmosfera democrática, que promova a autoconfiança, a autonomia e a autodeterminação, especialmente, para esses seres que estão em uma fase de sua existência demarcada pelo desenvolvimento, por experimentações, pela construção de suas identidades pessoais e sociais. E, inequivocamente, trata-se de uma relação dialética, na medida em que o protagonismo social por eles vivenciado os fortalece enquanto sujeitos, ao mesmo tempo em que, ao serem fortalecidos, fortalecida resta a democracia na sociedade. Razão pela qual reconhecer crianças e adolescentes como sujeitos de direito não é o fim último, mas o início de um processo para a permanente construção e reconstrução de qualquer Estado Democrático.

Com a finalidade de permitir a análise sobre como crianças e adolescentes podem contribuir para o debate e agenda públicos, a próxima seção debruça-se sobre o direito à participação, que já foi, inclusive, identificado como o direito mais violado da Convenção sobre os Direitos das Crianças (SMITH, 2002, p. 74).

\section{DIREITO À PARTICIPAÇÃO E POLÍTICAS PÚBLICAS}


We [the children] pledge an equal partnership in this fight or children's

rights. And while we promise to support the actions you take on behalf of children, we also ask you for your commitment and support in the actions we are taking because the children of the world are misunderstood. We are not the sources of problems; we are the resources that are needed to solve them.

We are not expenses; we are investments. We are not just young people, we are people and citizens of this world. Until others accept their responsibility to us, we will fight for our rights. We have the will, the knowledge, the sensitivity and the dedication. We promise that as adults we will defend children's rights with the same passion that we have now as children. We promise to treat each other with dignity and respect. We promise to be open and sensitive to our differences (ARRIETA; CHEYNUT, 2002) $)^{3}$

A comunidade mundial já se acostumou a ver Greta Thunberg, Malala Yousafzai, Ema González, Jack Andraka e Amika George, enquanto adolescentes, lutarem pelo respeito aos direitos de crianças e adolescentes e pelos direitos humanos como um todo (DAY, 2019). Estes exemplos não podem ser vistos como isolados, uma vez que o direito à participação é assegurado a todas as crianças e adolescentes.

A participação possui como pressuposto a liberdade de crianças e adolescentes de opinião e expressão, conforme os artigos 9, 12 e 13, da Convenção sobre os Direitos das Crianças; artigo $5^{\circ}$, incisos IV e IX, da Constituição da República Federativa do Brasil, e artigo 16, inciso II, do Estatuto da Criança e do Adolescente (UNICEF, 1989; BRASIL, 1988; 1990). Ou seja, participação enquanto liberdade de pensar, expressar-se e formar sua opinião sobre os assuntos que as circundam e a que a elas digam respeito, até mesmo no que se refere à sua formação política, filosófica e moral, o que não prescinde do acesso à informação e à educação (MÔNACO, 2005, p. 177; AMIN, 2019, p. 108). Disso se extrai que devem ter lugar de fala em todos os problemas que considerem importantes (VIVIERS; LOMBARD, 2013, p. 14). De todo modo, é importante demarcar que esse exercício da participação é, antes de tudo, um processo educativo, tanto para as crianças e adolescentes como também para todos os adultos.

\footnotetext{
${ }^{3}$ Nós [as crianças] prometemos uma parceria igualitária nesta luta ou nos direitos das crianças. E embora nos comprometamos a apoiar as ações que empreendem em nome das crianças, também vos pedimos o vosso empenho e apoio nas ações que empreendemos, porque as crianças do mundo são mal compreendidas. Não somos as fontes dos problemas; somos os recursos necessários para os resolver. Não somos as despesas; somos os investimentos. Não somos apenas os jovens, somos pessoas e cidadãos deste mundo. Até que outros aceitem a sua responsabilidade para conosco, lutaremos pelos nossos direitos. Nós temos a vontade, o conhecimento, a sensibilidade e a dedicação. Prometemos que, como adultos, defenderemos os direitos das crianças com a mesma paixão que temos agora que as crianças. Prometemos tratar uns aos outros com dignidade e respeito. Prometemos ser abertos e sensíveis às nossas diferenças (tradução nossa).
} 
Deve-se frisar que não é crível, em verdade, o exercício pleno da liberdade de opinião e expressão sem informações necessárias para conhecimento de problemas e dos fatos. Não é por outra razão que o artigo 17, da Convenção sobre os Direitos da Criança, trata das obrigações dos meios de comunicação de garantir esse acesso a informações e materiais às crianças e adolescentes (UNICEF, 1989; MÔNACO, 2005, p. 177).

Um questionamento válido neste sentido é: Que informações devem as crianças e adolescentes ter para exercer o direito de participação e liberdade de opinião e expressão? A resposta mais curta é no sentido de que devem ter acesso a toda informação que contribua para o exercício da sua autonomia. Todavia, este aspecto merece que se pontue que o direito a se desenvolver e crescer em condições de segurança potencializa o adequado exercício do direito e liberdades referidas, demonstrando a necessidade de minimizar danos.

Crianças e adolescentes devem ter informações acerca do direito à participação e às liberdades de opinião e expressão, sobre as possibilidades, consequências e impactos do exercício deles, assim como acerca de problemas públicos ou privados sobre os quais se debruçam, qual o objetivo da participação e expressão, como as decisões serão adotadas nos processos (administrativos e judiciais, por exemplo) em que estão envolvidos e como as visões deles impactam no processo decisório (MIDDEL et al., 2020, p. 716).

O princípio da transparência impõe que eles saibam o que esperar e o que está acontecendo. Não podem ser surpreendidos, na medida em que a surpresa, ou seja, a manifestação sem as informações necessárias pode comprometer o correto exercício dos direitos relativos à participação. $\mathrm{E}$ as informações transmitidas às crianças devem ser em uma linguagem que possa ser compreendida por elas (WOODHOUSE, 2003, p. 751), como a que é encontrada no site da Turminha do Ministério Público Federal (TURMINHA DO MPF, 2021).

Muito se discute sobre a competência de crianças para exercício desses direitos devido à condição de pessoas em desenvolvimento. Contudo, o afastamento desses direitos deve ser feito de forma excepcional, isto é, deve ser aceita a existência de capacidade para participar, pensar e expressar suas visões de mundo, devendo as exceções serem comprovadas e justificadas caso a caso (MCEWAN-STRAND; SKIVENES, 2020, p. 633; HENDERSONDEKORT; SMITS; VAN BAKEL, 2021, p. 87).

Usualmente e de forma paternalista, utiliza-se o princípio do melhor interesse para limitar a autonomia de crianças e adolescentes, o que, na prática, acaba por inutilizar toda a 
previsão normativa do direito de participação sob o argumento de que são vulneráveis e não devem ser sobrecarregados com questões adultas (HORSFALL, 2013; CASSIDY et al., 2017, p. 702; MIDDEL et al., 2020, p. 715). No entanto, essa visão paternalista evidencia desvalorização do potencial de crianças e adolescentes, nega a eles os direitos e significa vêlos como objeto de preocupação e objeto de decisões e não como sujeitos de direitos (VIVIERS; LOMBARD, 2013, p. 11-12), aproximando-se, sobremaneira, da doutrina da situação irregular.

A interpretação mais adequada é a de que crianças e adolescentes devem ser incluídos na definição do melhor interesse, sendo assim, com a participação deles e com a oferta de oportunidade para que possam expor seus pontos de vista (HENDERSONDEKORT; SMITS; VAN BAKEL, 2021, p. 90-91). Desse modo, tanto as práticas como a legislação, para assegurar os direitos à participação de crianças e adolescentes, precisam ser relidas e reinterpretadas para considerá-los atores aptos e que podem colaborar com a sociedade (KAPUR, 2006, p. 102). Além disso, os governos devem envolvê-los para avaliar leis que digam respeito a eles (HENDERSON-DEKORT; SMITS; VAN BAKEL, 2021, p. 82), não podendo as estruturas sociais, institucionais e familiares funcionarem como obstáculos para exercício desse direito.

Ressalta-se que, ao se assegurar o respeito aos direitos de participação, em especial, na esfera política e comunitária, tornam-se visíveis os direitos de crianças e adolescentes e eles passam a demonstrar interesse e a participar dos processos para construção de interpretações dos direitos humanos, do que se extrai a aceitação delas como atores políticos (SARMENTO; FERNANDES; TOMÁS, 2007, p. 202).

Considerando a vulnerabilidade e a condição de pessoas em desenvolvimento de crianças e adolescentes, há que se destacar a necessidade de que os adultos, em especial, seus genitores, guardiões e tutores, cooperem para suportar o exercício do direito à participação (HENDERSON-DEKORT; SMITS; VAN BAKEL, 2021). Entre as perguntas mais recorrentes quando se fala em participação infantil estão: com qual idade deve ser iniciada; e se existe algum parâmetro etário em que é obrigatória e/ou recomendada.

No caso brasileiro, podem ser extraídos os seguintes parâmetros, inclusive etários, relacionados à participação: (a) conceituação de criança como pessoa até doze anos de idade incompletos e de adolescente como aquela entre doze e dezoito anos de idade; (b) direito de preferencialmente "serem crianças e adolescentes serem ouvidos por equipe interprofissional" 
e multidisciplinar, com respeito ao grau "de desenvolvimento e grau de compreensão sobre as implicações da medida", assim como direito de terem suas opiniões devidamente consideradas; (c) previsão de que os maiores de doze anos de idade devem consentir com a colocação em família substituta; (d) liberdade de participar da vida comunitária e familiar, sem discriminação, e da vida política, na forma da lei, assim como de liberdade de opinião, expressão, crença, culto religioso, e de se divertir; (e) direito à participação de criança e adolescente em programa de acolhimento institucional ou familiar de programa de apadrinhamento; (f) direito de organização e de participação em entidades estudantis de criança e adolescente; (g) direito de crianças e adolescentes de serem ouvidos obrigatoriamente e participarem nos atos e na definição de medida de promoção de direitos e de proteção, sendo suas opiniões devidamente consideradas pela autoridade judiciária competente; (g) "competência da autoridade judiciária para disciplinar a participação de crianças e adolescentes desacompanhados em espetáculos públicos" e seus ensaios e em certames de beleza, que deve considerar a adequação do ambiente, conforme art. $2^{\circ}$ caput; art. 28, $\S 1^{\circ}$ e $2^{\text {o }}$; 16, II a VI; 19-B; 53, IV; 100, XII; 149, do Estatuto da Criança e do Adolescente (BRASIL, 1990, passim).

Ciente das disposições acima, poder-se-ia cogitar que adolescentes teriam direito à participação sem questionamentos e que crianças o teriam, sempre que possível, considerando seu estágio de desenvolvimento e grau de compreensão. Entretanto, parece mais adequado não considerar a idade isoladamente para restringir o direito de participação deles (HENDERSON-DEKORT; SMITS; VAN BAKEL, 2021, p. 87-93), mas, sim, partir da premissa de que eles têm direito de participação e competência para exercê-lo, salvo situações em que se demonstre que o estágio de desenvolvimento e grau de compreensão são impeditivos ao exercício do direito (MCEWAN-STRAND; SKIVENES, 2020, p. 633; HENDERSON-DEKORT; SMITS; VAN BAKEL, 2021, p. 87).

Ademais, deve-se ponderar previamente, caso seja imposta restrição ao direito de participação, se este direito não pode ser exercido com o auxílio de equipe multidisciplinar ou através do Promotor de Justiça (conforme o art. 178, II, do Código de Processo Civil; art. 127, caput, e art. 129, da Constituição da República; art. 141 e 201, do Estatuto da Criança e do Adolescente), que exerceria aqui a função de ombudsman para eles (WOODHOUSE, 2003, p. 752).

Outro questionamento a ser feito é sobre quem deve escutar e assegurar a 
participação. Uma possível resposta pode ser extraída do artigo 227, caput, da Constituição Federal, que destaca que é dever da família, da sociedade e do Estado proteger os direitos de crianças e adolescentes, sendo que o artigo $4^{\circ}$, do Estatuto da Criança e do Adolescente, fala em poder público em vez de Estado e acrescenta a comunidade. Estes não devem só escutar, mas dialogar com eles, seja em grupos ou separadamente para que eles possam se expressar mais livremente (MIDDLE et al., 2020, p. 716).

Seguindo a lógica do artigo 149 do Estatuto da Criança e do Adolescente, já os espaços para escuta e participação devem ser a eles adequados e amigáveis, de forma que não podem ser hostis, intimidantes, insensíveis e inadequados a eles (HORSFALL, 2013, p. 440). Em relação a quais vozes devem ser ouvidas e a quais crianças e adolescentes devem participar, a discussão passa pela idade e competência já analisadas anteriormente. O importante é assegurar que todos que queiram ser ouvidos e participar possam fazê-lo, desde que essas condutas não lhes causem danos, e de que sejam respeitados, também, os direitos correlatos de ter seus pontos de vista considerados, assim como sua liberdade de religião e privacidade (KIRK, 2019, p. 421). O respeito passa, sobretudo, pelo reconhecimento do direito de não se expressar e de não participar, caso não o desejem (SUTHERLAND, 2013, p. 344).

Parece coerente, ainda com o amplo exercício dos direitos citados, que crianças e adolescentes possam escolher a forma como desejam ser ouvidos e participar, podendo ser por meio de interposta pessoa (ex.: promotor de justiça, pais), por escrito, em oitiva judicial, em relato através de equipe multidisciplinar, através de vídeos, por gestos, por desenhos ou, até mesmo, através das redes sociais.

Os direitos referidos não são desprovidos de força. Para que não se tornem apenas símbolo e decoração, os conteúdos de suas falas devem ser sopesados pelos agentes, como já mencionado ao tratar da disciplina do Estatuto da Criança e do Adolescente sobre o tema. Com isso, é importante que as pessoas analisem o conteúdo das falas de crianças e adolescentes e não apenas quão bem elas se expressam, quão inteligentes ou mais próximas dos adultos elas são (INVERNIZZI; MILNE, 2002, p. 417).

Ainda nessa parte, deve-se pontuar que, além de um direito, a participação é meio para conquistas sociais, para a efetivação de outros direitos e "superação de desigualdades e violações cometidas contra crianças e adolescentes" (CEDECA CEARÁ, 2017, p. 26). Devese assegurar que crianças e adolescentes também reconheçam suas responsabilidades de 
contribuir para o bem comum, de avaliar o impacto de suas decisões sobre os direitos humanos de gerações futuras e proteger a igualdade (inclusive, a de gênero), assim como a possibilidade de contribuir para a construção do futuro que almejam (OSLER; STARKEY, 1998). Com sentido, suas falas serão mais bem ouvidas.

Uma das maiores preocupações entre os críticos à implementação da participação de crianças e adolescentes e ao direito de escuta de suas vozes é a sobrecarga de, eventualmente, serem responsabilizados pelo teor da decisão final, motivo pelo qual se sustenta, com base no dever de proteção, que essa responsabilidade seja deles afastada (SMITH, 2002, p. 75; HORSFALL，2013，p. 443; MCEWAN-STRAND; SKIVENES，2020; HENDERSONDEKORT; SMITS; VAN BAKEL, 2021, p. 93).

Outra preocupação recorrente, ainda mais quando se trata da participação de crianças e adolescentes em políticas públicas, é o risco de manipulação (INVERNIZZI; MILNE, 2002, p. 415), que exige para o seu afastamento a compreensão dos modelos de participação, que, segundo Hart (1993), são os seguintes: (a) manipulação - comumente ocorre quando crianças e adolescentes não compreendem os problemas e direitos a serem exercidos, que pode funcionar como uma forma de introduzi-los em processos políticos democráticos ou pode decorrer de consultas sem prestações de informações de que eles necessitam; (b) decoração frequente quando se vestem crianças e adolescentes com camisetas de lutas, mas eles não têm ideia da causa que representam ou mesmo da função desempenhada com o seu uso, representando utilização deles para chamar a atenção para certa luta; (c) participação simbólica - ocorre quando se permite a eles se expressar, mas não tem qualquer influência sobre o processo decisório pela falta de informação e de condições de exercer o direito de participação; (d) atribuídos, mas informados - exige que crianças e adolescentes compreendam os objetivos da causa e do chamamento à participação, conheçam os responsáveis pelo acionamento deles, tenham as informações necessárias para compreensão dos temas discutidos e sejam participantes voluntários; (e) realização de consulta, mas sem prestação de contas sobre o resultado desta; (f) iniciativa de adultos, com compartilhamento de decisões com crianças e adolescentes; ( $\mathrm{g}$ ) iniciada e dirigida por crianças e adolescentes; e (h) iniciativa infanto-juvenil e com decisões compartilhadas com os adultos (HART, 1993, passim).

O autor ainda pontua que apenas as letras "d" a "g" representam participação genuína (Ibid.), de tal forma que estas devem ser buscadas por todos para garantir que crianças sejam 
tratadas como pessoas, possam ter voz e participar de políticas públicas, em especial, as que dizem respeito aos direitos delas. Alguns exemplos de participações em políticas públicas por crianças e adolescentes serão trazidos na seção a seguir.

\section{EXPERIÊNCIAS E ESPAÇOS DE PARTICIPAÇÃO DE CRIANÇAS E ADOLESCENTES}

O primeiro exemplo a ser trazido é o Programa "Everyday Heroes" de crianças e adolescentes da Escócia, em que se visualiza o engajamento deles sobre que melhoramentos que os sobreviventes de violência de gênero (violência doméstica, estupro etc.) necessitam dos serviços e sistemas de justiça, e como podem auxiliar a sociedade e as vida das pessoas no que se refere à igualdade de gênero. O movimento exigiu atuação governamental através da apresentação "Safe Delivery Plan” (EVERYDAY HEROES, 2021). O segundo exemplo é o “Scotland Children's Parliament”, estabelecido em 1996, e que possui a função de auxiliar as autoridades locais a cumprir com as obrigações deles e proteger os direitos humanos, desenvolvendo, também, investigações sobre saúde mental e bem-estar, crianças e o coronavírus (COVID-19), mudança climática, dignidade na escola, dentre outros (CHILDREN'S PARLIAMENT, 2021).

Da Índia, é relevante citar o "Bal Mahapanchayat”, em que seus representantes trazem a voz das crianças para as discussões e ações relativas ao trabalho infantil e à educação (RIBHU; PEARSON, 2008, p. 12).

Percebendo a necessidade adolescentes a partir dos treze e adultos até vinte e quatro anos de idade serem ouvidas, a UNICEF estabeleceu uma comunidade chamada "Voices of Youth" para que eles possam exercer esse direito e para dar eco às vozes deles, em especial no que se refere a injustiças (UNICEF, 2019).

No Brasil, pode-se citar o Projeto "Juventude Quer Viver" da Pastoral da Juventude, inclusive, com assunção da "Campanha Nacional contra a Violência e o Extermínio de Jovens", que busca incentivar à luta pela garantia de direitos. Até mesmo temas que chamaram a atenção da mídia, como o caso Mariana Ferrer e o debate sobre participação política foram tratados pelo projeto (PASTORAL DA JUVENTUDE CNBB, 2014). A Pastoral da Juventude do Meio Popular (PJMP) merece registro especial:

A PJMP nasceu em 1978 no Recife, carregando grandes influências da Juventude Operária Católica (JOC). Um acontecimento marcante do seu nascimento foi o encontro realizado em 1978, reunindo animadores dos grupos de jovens do meio 
popular, remanescentes da JOC, em que decidiram criar um movimento de jovens do meio popular. Uma campanha recente realizada pela PJMP foi a "A Juventude Quer Viver", no combate à violência e extermínio da juventude (CEDECA CEARÁ, 2017, p. 27).

Historicamente, no Brasil, tem-se a experiência da organização autônoma do movimento estudantil, seja a União Nacional dos Estudantes (UNE), seja a União Brasileira dos Estudantes Secundaristas (UBES) que protagonizaram a campanha intitulada "Fora Collor", que levou ao impedimento do presidente Fernando Collor, e mais:

A UNE é uma das entidades que representa e organiza os estudantes no Brasil. Em
1937, o Conselho Nacional dos Estudantes criou a entidade, e os estudantes a partir
de então começaram a se organizar na UNE. Os primeiros anos de fundação foi o
período marcado pela Segunda Guerra Mundial, e os estudantes se colocaram
contrários ao nazi-fascismo, disputaram as ideias e pressionaram o Presidente do
Brasil na época (Getúlio Vargas) a tomar posição. A UNE participou e protagonizou
diversas lutas sociais, uma das mais marcantes foi a Campanha "Diretas Já" contra à
Ditadura Militar (1964-1985) (CEDECA CEARÁ, 2017, p. 27).

A Rede Orçamento e Participação Ativa (OPA) é uma boa prática que pode ser encontrada em Fortaleza, Ceará. Ela aborda o tema complexo do monitoramento realizado por adolescentes do orçamento público e das políticas destinadas à infância (CEDECA CEARÁ, 2011).

Outro caso emblemático é o G-38, uma comissão do Conselho Nacional dos Direitos da Criança e do Adolescente (CONANDA) formada por jovens de vinte e sete unidades da federação e onze membros de movimentos sociais que teve como objetivo assegurar o protagonismo de jovens na Conferência Nacional dos Direitos da Criança, realizada em abril de 2016 (FUNDAÇÃO TELEFÔNICA VIVO, 2016).

Além dos casos acima, ainda podemos citar o Movimento "Sem Terrinha", desenvolvido pelo Movimento dos Trabalhadores Rurais Sem Terra (MST) (MOVIMENTO DOS TRABALHADORES..., 2019); o Movimento Monitoramento Jovem de Políticas Públicas (MJPOP) da ONG Visão Mundial, com o objetivo de desenvolver capacidades para participação ativa de jovens e adolescentes em temas relacionados a violências, violações de direitos, racismo, segurança pública e pandemia (VISÃO MUNDIAL, 2021); e o Parlamento Juvenil do Mercosul, com o objetivo de fortalecer a participação de jovens na promoção da cidadania regional e que teve origem no marco do "Setor Educacional do Mercosul" (PARLAMENTO JUVENIL MERCOSUL, 2021).

Como visto, os espaços de participação dos movimentos sociais são fundamentais e de valor histórico na luta por direitos. Pela ação desses movimentos, por exemplo, tem-se, em 
termos de direitos da infância e da juventude, o Estatuto da Criança e do Adolescente. Outros movimentos destacam-se no cenário nacional: o Movimento Negro Unificado (MNU), os diversos Movimentos de Mulheres, os Movimentos Indígenas, o Movimento dos Trabalhadores Rurais Sem Terra (MST), o Movimento dos Trabalhadores Sem Teto (MTST), os Movimentos de Quilombolas, os Movimentos de LGBTQIA+, entre outros.

Não se pode deixar de mencionar o Movimento de Ocupações das Escolas Públicas que ocorreu em todo o país, entre 2015 e 2016, momento em que estudantes secundaristas das redes públicas estaduais foram os atores sociais mais importantes de um sem-número de reivindicações vinculadas não somente à pauta da educação pública, mas, também, em solidariedade às reivindicações docentes. Os estudantes secundaristas ocuparam as escolas e as ruas pelo cumprimento do direito constitucional à educação pública de qualidade. Um exemplo disso, foi o estado do Ceará, onde, de abril a agosto de 2016, mais de 60 escolas estaduais foram ocupadas por seus estudantes, como forma de denunciar os problemas existentes e por uma pauta de exigências de condições básicas para o funcionamento escolar e de melhoria do ensino. Aqui, o espaço democrático dos grêmios escolares revela-se privilegiado para a participação de crianças e adolescentes como sujeitos para quem deve ser garantido o direito de decidir sobre os rumos da educação e da qualidade do ensino.

Tendo em vista as práticas de mobilização e participação acima, parece adequado que as crianças e adolescentes tenham voz também sobre o destino do dinheiro existente no Fundo Especial para Infância e Adolescente, previsto nos artigos 245 a 258, 154, 214 e 260, do Estatuto da Criança e do Adolescente, e no Fundo de Direitos Difusos trazido pela Lei $\mathrm{n}^{\circ}$ 7.347/1985, em especial, porque podem auxiliar na definição dos projetos prioritários e acompanhar a implementação de políticas públicas com estes recursos.

Também é importante que crianças e adolescentes possam participar de processos estruturais e de casos de julgamento de estado de coisas inconstitucional que digam respeito a seus direitos (RODRÍGUEZ-GARAVITO, 2010-2011), como no caso da ação civil pública ajuizada, questionando o acolhimento institucional por tempo superior ao teto legal e a ausência de implementação de acolhimento familiar (conforme RESP 1854842/CE, Rel. Ministra NANCY ANDRIGHI, TERCEIRA TURMA, julgado em 02/06/2020, DJ e 04/06/2020).

Ainda se demanda maior estruturação para assegurar o direito à participação de crianças e adolescentes em políticas públicas, sejam as governamentais, sejam as realizadas 
pela sociedade civil organizada. Além disso, deve-se garantir a participação de crianças, inclusive, em associações genuínas, ou seja, sem manipulação que as transforme apenas em exposição da vontade e dos projetos de adultos.

\section{CONCLUSÃO}

Apesar da necessidade de discussão sobre outros aspectos do direito de participação infanto-juvenil, podem ser extraídas do presente artigo as seguintes conclusões: (a) a condição de crianças e adolescentes como sujeitos de direitos e atores sociais, com possibilidade de contribuir para a definição da agenda pública; (b) que eles podem participar em questões relativas a políticas públicas e (c) que essa participação encontra limites apenas decorrentes da preservação deles contra danos, que podem ser extraídos do princípio da proteção integral, mas que essa limitação deve ser traçada caso a caso, presumindo-se a existência de competência para a participação.

Outrossim, importante demarcar que, na prática, se faz necessário compreender os mecanismos garantidores e buscar interagir com os espaços de participação e controle, visando a afirmação da participação proativa social e cidadã de crianças e adolescentes. Razão pela qual se revela de importância vital garantir a participação desses sujeitos nas distintas esferas da vida, especialmente na esfera pública. Assim, os diferentes espaços de discussão e deliberação de políticas públicas precisam ser considerados de interesse da infância e da juventude.

Foram citados vários exemplos que demonstraram a importância e a viabilidade da liderança e do protagonismo infanto-juvenil no que se refere aos direitos humanos, mas não só os deles, assim como de contribuir para a construção de projeto de sociedade que valorize esses direitos, com preocupações que perpassam questões relativas à violência de gênero e direito ao meio ambiente saudável, em especial, diante da mudança climática.

A mensagem geral do presente ensaio é a de que a atitude social precisa mudar para refletir a imposição e, até mesmo, como respeito à condição humana e de sujeitos de direitos, que crianças e adolescentes tenham vez e voz, não sejam inviabilizados e possam, através da sua própria participação, garantir o respeito e a implementação de seus direitos. Afinal, uma postura diversa fornece a eles a impressão equivocada de que certas pessoas podem ser tolhidas de seus direitos, isto é, de que os processos de exclusão podem vir a ser aceitáveis, o que gera preocupações com o destino das futuras gerações e dos direitos humanos. 
Esta mensagem já foi abraçada por diversas crianças e adolescentes, mas os caminhos ainda precisam ser traçados e as portas abertas para o direito de participação no Brasil, como nas palavras do poeta espanhol Antonio Machado (MACHADO, 2009): "Caminhante não há caminho, / se faz caminho ao caminhar [...]”.

\section{REFERÊNCIAS}

AMIN, Andrea Rodrigues. Dos Direitos Fundamentais. In: MACIEL, Kátia Regina Ferreira Lobo Andrade (Org.). Curso de direito da criança e do adolescente: aspectos teóricos e práticos. São Paulo: Saraiva Educação, 2019. 1264 p. p. 82-148.

ARRIETA, Gabriela Azurduy; CHEYNUT, Audrey. A world fit for children. Child Care Exchange, 14 de maio de 2002. Disponível em: https://www.childcareexchange.com/eed/issue/26/. Acesso em: 03 set. 2021.

ATWOOD, Barbara. The Voice of the Indian Child: Strengthening the Indian Child Welfare Act through Children's Participation. Arizona Law Review, [S. l.] v. 50, n. 1, p. 127-15, 2008.

BAXI, Upendra. Politics of reading human rights: inclusion and exclusion within the production of human rights. In: MECKLED-GARCIA, Saladi; ÇALI, Basak (Orgs.). The legalization of human rights: multidisciplinary perspectives on human rights and human rights law. Nova Iorque: Routledge, 2006. 202 p. p. 182-200.

BECERRO, Verónica; GUERRINI, Lucía. Derechos bajo la alfombra: políticas públicas y participación efectiva de la infancia. Por Escrito, Buenos Aires, AR, n. 13, p. 24-33, 2019.

BRASIL. Constituição da República Federativa do Brasil de 1988. Brasília: Planalto, 1988. Disponível em: http://www.planalto.gov.br/ccivil_03/constituicao/constituicao.htm. Acesso em: 03 set. 2021.

BRASIL. Lei $N^{\circ}$ 8.069, de 13 de julho de 1990. Dispõe sobre o Estatuto da Criança e do Adolescente e dá outras providências. Brasília: Planalto, 1996. Disponível em: http://www.planalto.gov.br/ccivil_03/leis/18069.htm. Acesso em: 03 set. 2021.

BREELAND, N. R. The Army You Created: Combating the Issue of Sexual Assault in College and Quasi-Professional Sports. Mississippi Sports Law Review, v. 8, n. 1, p. 1-32, Spring, 2019.

CASSIDY, C.; CONRAD, S.; DANIEL, M.; FIGUEROI-REGO, M.; KOHAN, W.; MURRIS, K.; WU, X.; ZHELYAZKOVA, T.; Being children: children's voices on childhood. The International Journal of Children's Rights, Leiden, NE, v. 25, p. 698-715, 2017.

CEDECA CEARÁ. Rede orçamento e participação ativa (REDE OPA) celebra 6 anos de existência. CEDECA CEARÁ, 1 ago. 2011. Disponível em: http://cedecaceara.org.br/site/index.php/2011/08/01/602/. Acesso em: 03 set. 2021. 
CEDECA CEARÁ. Participação política de crianças e adolescentes. 2017. Disponível em: http://cedecaceara.org.br/site/wp-content/uploads/2019/02/Cartilha-direito-aparticipa\%C3\%A7\%C3\%A3o.pdf. Acesso em: 03 set. 2021.

CHENEY, Kristen E. Killing Them Softly: Using Children's Rights to Empower Africa's Orphans and Vulnerable Children. International Social Work, London, UK, v. 56, n. 1, p. 92-102, jan. 2013.

CHILDREN'S PARLIAMENT. Giving ideas a voice. 2021. Disponível em: https://www.childrensparliament.org.uk/. Acesso em: 03 set. 2021.

DAY, Harvey. 5 adolescentes que estão tentando mudar o mundo. BBC News Brasil, 26 de abril 2019. Disponível em: https://www.bbc.com/portuguese/geral-48046264. Acesso em: 02 set. 2021.

EVERYDAY HEROES. Children and young people committed to working together with people in power to make a safer and more equal Scotland. 2021. Disponível em: https://everydayheroes.sps.ed.ac.uk/. Acesso em: 03 set. 2021.

FUNDAÇÃO TELEFÔNICA VIVO. O protagonismo jovem na Conferência Nacional dos Direitos da Criança e do Adolescente. 1 de fevereiro de 2016. Disponível em: https://fundacaotelefonicavivo.org.br/noticias/o-protagonismo-jovem-na-conferencianacional-dos-direitos-da-crianca-e-do-adolescente/. Acesso em: 03 set. 2021.

GOODALE, Mark. Locating rights, envisioning law between the global and local. In:

MERRY, Sally Engle. The practice of human rights: trackling law between the global and local. Nova Iorque: Cambridge University Press, p. 1-38, 2007.

GROSMAN, C. P.; HERRERA, M. The child's right to be listened in family proceedings in Argentina. International Survey of Family Law, [S.l.], n. 39, p. 39-64, 2009.

HART, Roger A. La Participación de los Niños: De la Participación Simbólica a la Participación Autentica. Ensayos Innocenti, [S. l.] n. 4, p. 1-45, 1993.

HENDERSON-DEKORT, Emmie; SMITS, Veronica; VAN BAKEL, Hedwig. The Meaningful Participation and Complex Capacities of Children in Family Law: Based on Transdisciplinary Perspectives and Articles of the United Nations Convention on the Rights of the Child. The International Journal of Children's Rights, Leiden, NE, n. 29, p. 78-98, 2021 .

HORSFALL, Briony. Breathing Life into Children's Participation: Empirical Observations of Lawyer-Child Relations in Child Protection Proceedings. New Zealand Law Review, Auckland, NZ, n. 3, p. 429-444, 2013.

INVERNIZZI, Antonella; MILNE, Brian. Are children entitled to contribute to international policy making: a critical view of children's participation in the international campaign for the elimination of child labour. The International Journal of Children's Rights, Leiden, NE, v. 10, n. 4, p. 403-402, 2002. 
INVERNIZZI, Antonella; WILLIANS, Jane (Orgs.). The Human Rights of Children: from visions to implementation. Nova Iorque: Routledge, 2016. 372 p.

KAPUR, Ratna. Revisioning the role of law in women's human rights struggles. In: MECKLED-GARCÍA, Saladin; ÇAH, Basak (Orgs.). The legalization of Human Rights: multidisciplinary perspectives on human rights and human rights law. Nova Iorque: Routledge, p. 101-116, 2006.

KIRK, Tracy. Children as Human Rights Defenders: a participatory approach. Edinburgh Law Review, Edinburgh, ES, v. 23, n. 3, p. 417-423, 2019.

MACHADO, Antonio. Caminhante não há caminho, se faz caminho ao caminhar. Banco de Poesias, 13 de agosto de 2009. Disponível em: https://cdeassis.wordpress.com/2009/08/13/os-caminhos-de-antonio-machado. Acesso em: Acesso em: 03 set. 2021.

MCEWAN-STRAND, Amy; SKIVENES, Marit. Children's capacities and role in matters of great significance for them: an analysis of the Norwegian county boards' decision-making in cases about adoption from care. The International Journal of Children's Rights, Leiden, NE, v. 28, p. 632-665, 2020.

MIDDEL, Floor; POST, Wendy; LÓPEZ, Mónica López; GRIETENS, Hans. Participation of children involved in the child protection system: validation of the meaningful participation assessment tool (MPAT). Child Indicators Research, [S. l.], v. 14, p. 713-735, 2021.

MÔNACO, Gustavo Ferraz de Campos. A proteção das crianças no direito internacional. Belo Horizonte: De Rey, 2005. 376 p.

MOVIMENTO DOS TRABALHADORES RURAIS SEM TERRA. Sem terrinhas na construção do movimento. MST, 21 de fevereiro de 2019. Disponível em: https://mst.org.br/2019/02/21/sem-terrinhas-na-construcao-do-movimento/. Acesso em: 03 set. 2021.

MUNOZ RODRIGUEZ, Mariela; VUANELLO, Roxana. Children's Rights in Their Own Words. New Challenges for Its Political Acknowledgement. Estudios Socio-Juridicos, v. 23, n. 1, p. 319-346, jan./jun. 2021.

OSLER, Audrey; STARKLEY, Hugh. Children's rights and citizenship: some implications for the management of schools. The International Journal of Children's Rights, Leiden, NE, v. 6, n. 3, p. 313-334, 1998.

PARLAMENTO JUVENIL MERCOSUL. Sobre o PJM. 2021. Disponível em: http://parlamentojuvenil.educ.ar/?page_id=570. Acesso em: 03 set. 2021.

PASTORAL DA JUVENTUDE CNBB. A Juventude quer viver! 2014. Disponível em: https://www.pj.org.br/eixos/linhas-de-acao/a-juventude-quer-viver/. Acesso em: 03 set. 2021.

PÖSÖ, Tarja; ENROOS, Rosi. The representation of children's views in finish court decisions regarding care orders. The International Journal of Children's Rights, Leiden, NE, v. 25, p. 736-753, 2017. 
PROUT, Alan. Children's participation: control and self-realization in British late modernity. Children \& Society, [S. l], v. 14, p. 304-315, 2000.

RIBHU, Bhuwan; PEARSON, Nancy L. Building child friendly villages: using villages strengths to combat child labour and other exploitative practices. Minneapolis: The Center for Victims of Torture, 2008. $22 \mathrm{p}$.

RODRÍGUEZ-GARAVITO, César. Beyond the courtroom: the impact of judicial activism on socioeconomic rights in Latin American. Texas Law Review, Texas, US, v. 89, p. 16691698, 2011.

RODRIGUEZ, Mariela Munoz; VUANELLO, Roxana. Children's rights in their own words: new challenges for its political acknowledgement. Estudios Socio-Juridicos, Rosario, CO, v. 23, n. 1, p. 319-346, jan./jun. 2021.

SARMENTO, Manuel Jacinto; FERNANDES, Natália; TOMÁS, Catarina. Políticas públicas e participação infantil. Educação, Sociedade e Culturas, Porto, PT, n. 25, p. 183-206, 2007.

SECCHI, Leonardo; COELHO, Fernando de Souza; PIRES, Valdemir. Políticas Públicas: conceito, casos práticos e questões de concurso. São Paulo: Cengage Learning, 2020. 200 p

SHIVJI, I. G. Perspectives on human rights: an introduction. [S. l:] FAHAMU BOOKS, 2002 .

SMITH, Anne B. Interpreting and supporting participation rights: contributions from sociocultural theory. The International Journal of Children's Rights, Leiden, NE, v. 73, n. 1, p. 73-88, 2002.

SUTHERLAND, Elaine E. Listening to the Voice of the Child: The Evolution of Participation Rights. New Zealand Law Review, [S. l.], v. 2013, n. 3, p. 335-356, 2013.

THUNBERG, Greta. Read Greta Thunberg's full speech at the United Nations Climate Action Summit. NBC News, 23 set. 2019. Disponível em: https://www.nbcnews.com/news/world/read-greta-thunberg-s-full-speech-united-nationsclimate-action-n1057861. Acesso em: 02 set. 2021.

TOMÁS, Catarina. Participação não tem idade: participação das crianças e cidadania da infância. Contexto \& Educação, [S. l], ano 22, n. 78, p. 48-68, jul./dez. 2007.

TURMINHA DO MPF. Turminha do MPF (Página Inicial). 2021. Disponível em: https://turminha.mpf.mp.br/. Acesso em: 03 set. 2021.

UNICEF UNITED NATIONS INTERNATIONAL CHILDREN'S EMERGENCY FUND. Convenção sobre os Direitos da Criança. Nova Iorque, 20 de novembro de 1989. Disponível em: https://www.unicef.org/brazil/convencao-sobre-os-direitos-da-crianca. Acesso em 03 set. 2021.

UNICEF UNITED NATIONS INTERNATIONAL CHILDREN'S EMERGENCY FUND. Voices of Youth. 2019. Disponível em: https://www.voicesofyouth.org/. Acesso em 03 set. 2021. 
UNICEF UNITED NATIONS INTERNATIONAL CHILDREN'S EMERGENCY FUND. Situação das crianças e dos adolescentes no Brasil. 2021. Disponível em: https://www.unicef.org/brazil/situacao-das-criancas-e-dos-adolescentes-no-brasil. Acesso em: 03 set. 2021.

VERONESE, Josiane Rose Petry. Art. $3^{\circ}$, Título I - Das Disposições Preliminares, Livro I Parte Geral. In: VERONESE, Josiane Rose Petry; SILVEIRA, Mayra; CURY, Munir (Orgs.). Estatuto da Criança e do Adolescente comentado: comentários jurídicos e sociais. 13. ed., São Paulo: Malheiros, 2018. 1248 p. p. 58-62.

VISÃO MUNDIAL. Monitoramento Jovem de Políticas Públicas. 2021. Disponível em: https://visaomundial.org.br/mjpop. Acesso em: 03 set. 2021.

VIVIERS, Andries; LOMBARD, Antionette. The ethics of children's participation: fundamental to children's rights realization in Africa. International Social Work, London, UK, v. 56, n. 1, p. 7-21, jan. 2013.

WOODHOUSE, Barbara Bennett. Enhancing Children's Participation in Policy Formation. Arizona Law Review, [S. l.], v. 45, n. 3, p. 751-764, 2003. 